\title{
Imaginação e criação históricas na história global: combates pela história social dos protestos e movimentos sociais na América Latina
}

\author{
Historical imagination and creation in global history: fighting for the \\ social history of protests and social movements in Latin America
}

\section{Luiz Felipe Cezar Mundim*}

\begin{abstract}
Resenha do livro: ANDUJAR, Andrea \& BOHOSLAVSKY, Ernesto (ed.). Todos estos años de gente: historia social, protesta y política en América Latina. Los Polvorines: Universidad Nacional de General Sarmiento, 2020.
\end{abstract}

Palavras-chave: protestos; movimentos sociais; América Latina.

Keywords: protests; social movements; Latin America.

\begin{abstract}
7 ODOS EStOS Años DE GENTE (2020), título do livro recém-lançado pela Ediciones UNGS, é o nome de uma música de Luis Alberto Spinetta, gravada com Fito Páez em 1986. A música remete ao passar do tempo e aos vínculos entre as pessoas, conforme nos dizem Andrea Andújar e Ernesto Bohoslavsky, editores do livro e autores da apresentação. Esses dois aspectos da música são anunciados como elementos da característica central do livro: a combinação entre a reflexão histórica e o estudo das relações sociais. Resultado da mesa redonda La historia y la protesta en América Latina, proposta por Andújar e Bohoslavsky no contexto do Segundo Congreso Internacional de la Asociación Latinoamericana e Ibérica de Historia Social (ALIHS), ocorrido em Buenos Aires em 2017, o livro traz cinco textos resultados das contribuições dos pesquisadores convidados, e mais um do autor espanhol José Antonio Piqueras, que abre o livro.
\end{abstract}

\footnotetext{
* Doutor em História pela Universidade Federal do Rio Grande do Sul (UFRGS). Pós-doutorando no Centro de Pesquisa em História Social da Cultura (CECULT), da Universidade Estadual de Campinas (UNICAMP). ORCID: https://orcid.org/0000-0003-0684-7918. E-mail: luizmundim@gmail.com.
} 
Apresentado assim, em que um encontro é seguido por uma publicação, o livro pode ser tomado como apenas mais uma publicação acadêmica pro forma, o que certamente não condiz com a experiência da sua leitura. Os pesquisadores tinham como demanda, nessa mesa redonda, a reflexão em torno do questionamento a respeito da contribuição que a história social poderia trazer para a compreensão da história do tempo presente da América Latina, em termos de estudo das ações coletivas de protesto. Uma segunda questão, sobre os vínculos entre o exercício profissional da história e os movimentos ou organizações sociais e políticas que dinamizam essas ações no contexto atual, também deveria ser perseguida pelos convidados.

Poderíamos, então, esperar estudos de caso isolados, em mais um exercício linear de comparação delimitado pelas fronteiras nacionais. Entretanto, conforme avançamos nos capítulos, o que vemos, ou lemos, é uma sequência dinâmica de temas e abordagens que surpreendem pela heterogeneidade, sem perder o diálogo pretendido pela proposta original dos editores. O livro, como um todo, abarca desde a evolução da história social como abordagem e definição do método histórico e seus dilemas mais recentes na América Latina, passando pelo relato autobiográfico e chegando até casos específicos das relações entre a história social e determinadas ações coletivas de confronto político a partir de olhares sobre temas relacionados ao Brasil, México, Bolívia e Argentina. A história social latino-americana, nos dizem os editores, possui características singulares, onde os historiadores desenvolveram seus trabalhos com preocupação e compromisso vinculados à realidade vivida em seus países. Esse engajamento político no trabalho intelectual, que evoluiu ao longo da segunda metade do século $X X$, em sintonia com os fenômenos políticos e sociais nos quais os historiadores e cientistas sociais se viam confrontados, conforme os autores apontam, é bastante marcado no caso da América Latina.

No primeiro capítulo, Piqueras advoga em defesa da história social como própria definição de um conhecimento histórico possível, ao contrário da tentativa de identificá-la como especialidade acadêmica. No texto, que leva o título Tarea y promesa de la imaginación histórica, o autor assinala que a história social estabelece um antes e um depois na construção da ciência histórica, o que faz dela algo como um grande edifício de bases teóricas e metodológicas fortes o suficiente para resistir aos constantes ataques que sofreu desde os anos de 1980, pelo menos.

Piqueras aponta para a necessidade de imaginação histórica, como contraponto ao fantasiar, na realização da história social e, por fim, do conhecimento histórico. Para indicar como tal tarefa é possível, resgata a trajetória de Olympe de Gouges, a partir de Joan Scott, ressaltando as categorias de imaginação ativa e passiva, em jogo no período revolucionário, e de como Gouges quebrou com a ideia de que às mulheres estava relegado o lugar da imaginação passiva apenas. Com Gouges, e sua história contada por Scott, que retoma o ato de imaginar criativamente ao problematizar uma determinada trajetória, a mulher cria o seu 
lugar, o seu espaço e sua atuação na vida pública e na história, estratégia textual à qual Mirta Zaida Lobato se aproxima no terceiro capítulo.

Com o autor Wright Mills, Piqueras redesenha o papel da imaginação na elaboração de qualquer ciência social, na medida em que é por meio da imaginação que o historiador consegue transitar entre um tema e outro, passar de uma perspectiva a outra (da política à psicológica, de uma família às comparações dos pressupostos nacionais do mundo etc.). Assim é que a história social, como história da sociedade, cumpre sua função compreensiva e explicativa, o que - segundo o autor - a coloca diante dos problemas políticos e intelectuais que marcam a atualidade, mais do que uma especialidade em meio a tantas outras na história.

No segundo capítulo, que leva o título Algunas reflexiones sobre la historia y la protesta social, o historiador mexicano Carlos Illades, por meio de um procedimento um tanto mais raro na historiografia social brasileira, fundamenta-se no aparato conceitual proveniente do campo das ciências sociais, em especial com a teoria do confronto político de autores como Sydnei Tarrow e Charles Tilly. O resultado é um olhar mais geral, e nem por isso generalista, uma vez que se trata de uma bela síntese de pesquisas pregressas, e que contribui com o esforço da história social na busca pela variação das escalas de análise.

A partir da caracterização dos novos repertórios de ação coletiva, das demandas e das campanhas de quatro movimentos sociais que detonaram protestos massivos no México, desde a década de 1990 aos dias atuais, o autor tenta traçar, em dez páginas muito precisas, um possível campo de ação dos historiadores sociais diante da dinâmica dos sujeitos coletivos. Alguns movimentos e protestos, como o neozapatismo, os arrendadores de Atenco, o Movimiento por la Paz com Justicia y Dignidad (MPJD), o movimento pelos 43 estudantes desaparecidos de Ayotzinapa e o movimento YoSoy32 (de 2011-2012, pelas vidas perdidas para o tráfico) são destacados como movimentos recentes em que o tradicional repertório de luta dos movimentos sociais nacionais do século XX já não se faz presente, ainda que a maior parte deles sejam voltados ao confronto com o governo federal.

Illades, com a breve exposição das características desses movimentos, aposta na possibilidade de inspiração aos historiadores pelo engajamento das mobilizações coletivas, retomando o papel social do intelectual. Essa inspiração estaria presente, especialmente, no funcionamento em rede e na perspectiva transnacional dos movimentos, traduzidos não apenas no fazer historiográfico pautado pelos conflitos da sociedade e pela premissa comparativa, mas também pelo compromisso do historiador em tornar públicas e visíveis as suas investigações e posicionamentos, participando e intervindo no debate público.

No capítulo dois, a historiadora Mirta Zaida Lobato propõe revisitar a história do protesto social a partir de uma perspectiva de gênero, buscando tornar visível alguns aspectos dos movimentos sociais que tradicionalmente foram omitidos, pelo que chama de "La miopia de lo visible" - expressão que dá título ao capítulo. A autora divide o texto em quatro partes, 
o que interessa pelo fato de que todas as partes constituem formulações de problemas gerais e específicos da história social na América Latina. Os problemas dialogam entre si, e tem na história do protesto, pela perspectiva das mulheres, um ponto de partida para os estudos dos protestos na América Latina. A participação das mulheres nos movimentos e protestos, conforme a autora nos conduz pelo texto, se torna visível pela conexão estabelecida entre a rica participação delas nos movimentos e pelas especificidades universalistas de suas demandas particulares de gênero, geralmente voltadas para o bem-estar em casa e na comunidade. Desde a forte participação das mulheres no movimento operário no começo do século XX até a retomada da especificidade de gênero nos protestos das últimas décadas, a ação coletiva das mulheres teria se estabelecido pelo caráter de resistência popular e atua em nome de demandas sociais frente a sociedades crescentemente mais hostis. A autora reivindica, então, uma história social do protesto na América Latina que busque romper com o nacional, e que seja integradora e atenta às diversas experiências históricas, atenta à heterogeneidade das experiências de protestos, em sua diversidade de práticas, observados por ângulos diversos.

Na sequência, o texto Al final del arco-íris - Sobre los homosexuales como sujetos de interés en la academia mexicana. Legitimidad y apertura de espacios sociales, do historiador e antropólogo Rodrigo Laguarda, se apresenta como um belo intervalo no livro, se pudermos assim localizá-lo. Escrito como um ensaio de ego-história, o exercício da escrita de si que Laguarda realiza nos lança a um suspiro pelas distâncias visíveis e invisíveis entre o trabalho acadêmico e as lutas sociais. Em um sentido, após a reflexão sobre a sua trajetória como estudante e, enfim, como profissional da história, o autor julga ser o lugar acadêmico por si só um campo de luta política e social. Isso se dá na medida em que ele mesmo procura incluir, e dar visibilidade, não só a temas marginais, como é o caso da homossexualidade que constitui o tema de suas pesquisas, mas também espaço e voz a estudantes e aspirantes a pesquisadores, usualmente excluídos do curso normal e tradicional acadêmico.

Em outro sentido, o autor julga com brevidade as lutas atuais como desprovidas de número e motivação, o que talvez denuncie algum alheamento das realidades das lutas sociais e populares, algo reconhecido pelo próprio Laguarda. O estilo ensaístico e o ponto de partida autobiográfico, sejam eles motivados por uma perspectiva decolonial, que vise desprovincializar o debate em torno da luta dos homossexuais - já que, um dos maiores esforços do autor é deslocar o espaço de produção de conhecimento sobre os homossexuais mexicanos, dos Estados Unidos de volta para o México -, ou sejam eles simplesmente resultados do formato textual memorialístico definido previamente, e possivelmente alhures ao projeto do livro, são grandes contribuições para o debate sobre o protesto na América Latina. A honestidade em relação ao lugar de onde se fala, o olhar crítico sobre esse mesmo lugar, que é a academia, associado ao reconhecimento da complexidade social a que o conhecimento deve atingir e se voltar, são fatores 
fundamentais em qualquer proposta que se faça para discutir os movimentos sociais voltados à conquista da liberdade ao longo da história. Laguarda pretende mostrar esses fatores, então, com a sua própria história, constituindo-a como fonte de conhecimento sobre o tema dos protestos levantado pelo livro.

O capítulo seguinte, Historia de la esclavitud, movimentos sociales y políticas públicas contra el racismo em Brasil, da historiadora Silvia Hunold Lara, única brasileira no livro, vem na sequência abrindo o que poderíamos chamar de parte final, em que temas mais específicos, ou especializados, são desenvolvidos de forma mais vertical a partir do debate historiográfico que os integram. Nesse texto, Lara estabelece uma relação entre o percurso do movimento negro no Brasil, suas pautas e tendências na luta contra o racismo e a discriminação racial desde o início do século XX, e os caminhos percorridos pelo pensamento social brasileiro e a historiografia sobre a escravidão e sua abolição.

Essa consonância entre o pensamento social, a historiografia, e o movimento negro teria sua origem, de certa forma, na antinomia entre escravidão e liberdade, apropriada pelo movimento abolicionista e perpetuada até pelo menos os anos setenta e oitenta. Cristalizada como postulado historiográfico a partir dos anos trinta, essa dicotomia se firmou nas polaridades entre categorias diversas, como o arcaico e o moderno. Com autores como Florestan Fernandes e Octavio lanni, o esforço se volta a denunciar o mito freyreano da democracia racial e, então, a análise se concentrava na ideia de que os negros teriam sido excluídos da sociedade de classes, em consequência do que foi chamado de substituição do trabalho escravo pelo livre (branco e imigrante). O racismo, assim, estava na própria marginalização dos negros no processo de desenvolvimento capitalista brasileiro, e a ênfase recaía nas questões de classe, e não de raça propriamente.

Os estudos feitos a partir dos anos oitenta e noventa questionaram diretamente as teses de transição e substituição da mão de obra, ampliando o espectro da ideia de liberdade e sua conquista, dando ênfase aos escravos enquanto sujeitos e agentes históricos em suas lutas e conquistas cotidianas. De toda forma, a militância continuava a ter como referência a obra clássica de Florestan Fernandes, e a grande mudança teria vindo de fora, pela instituição da lei n. 10.639 de 2003, que tornava obrigatório o ensino da história e cultura afro-brasileiras em escolas primárias e secundárias. Ainda que o estudo da experiência do racismo no Brasil venha sendo produzido em uma academia que segue elitista e branca - daí a importância dos historiadores no debate sobre a implementação da política de cotas raciais nas universidades públicas -, diz Silvia Lara, o lastro dos debates e das conquistas obtidas nos últimos anos devem significar uma intensificação do diálogo entre os historiadores e o movimento negro.

O texto De puentes y precipícios - Uma perspectiva sobre los vínculos entre historia/s y movimientos sociales en Bolivia (de 1970 a la actualidad), da historiadora Rossana Barragán Romano, é o sexto e último capítulo. A autora, da mesma forma que Silvia Lara no capítulo 
anterior, tem como proposta observar as aproximações entre a produção acadêmica sobre a população indígena boliviana e suas possíveis influências nas ações coletivas indígenas.

Romano sustenta que a Bolívia deve ser o país sul-americano em que a relação entre os acadêmicos, especialmente os intelectuais indígenas, e os movimentos sociais se deu de forma mais próxima e articulada. Um dos motivos dessa aproximação, que carrega o significado do título do texto, se deu pelo trânsito político entre os acadêmicos que se dedicavam a estudar a história e a sociedade do território boliviano, os povos e comunidades indígenas. Se em um dado momento, nas décadas anteriores a 1980, a questão era trabalhada e estudada como um problema da "visão dos vencidos", centrada na classe, voltada a sublinhar os antagonismos de organização da revolução em que os sujeitos são proletários e camponeses, com o estímulo intelectual à criação da luta operária tradicional via sindicatos, a partir da década de 1980, se observaria uma mudança. Da exploração de classe, as análises se voltam à opressão, em que se nega a derrota. A partir de então, o sujeito central protagonista se firma no indígena e povos indígenas, que passam a ser apoiados pela luta por território e cultura, orientando inclusive uma nova forma de identidade nacional.

Um exemplo dessa aproximação teria sido a parceria entre Evo Morales Ayma e seu vice, Álvaro García Linera, intelectual do grupo Comuna, que juntos garantem a eleição presidencial de 2005. Essa parceria, a autora nos faz saber, se deu após grave crise política e social, também estimulada por demandas de grupos indígenas motivados intelectualmente e politicamente em direção à dissolução do estado boliviano - o que representa os "precipícios" no título -, que havia levado à destituição do governo neoliberal de Sánchez de Lozada em 2003.

Outro motivo, que levou a essa relação de proximidade entre acadêmicos e indígenas, é o fato de ter sido criado um ambiente acadêmico da história e sociologia tardiamente (na década de 1970), e da antropologia e arqueologia ainda depois (década de 1980). Além disso, esse ambiente ainda estaria marcado pela grande precariedade e instabilidade institucional no país, em que o trabalho dos acadêmicos e acadêmicas costuma se sustentar por iniciativa pessoal e individual, enquanto o docente costuma receber em muitos casos por hora/aula, sem benefícios.

Fruto de um conjunto de trabalhos que refletem a maturidade historiográfica e profissional dos autores, Todos estos años de gente: historia social, protesta y política en América Latina soma-se a esse esforço perene pela construção do conhecimento histórico sobre a América Latina que visa integração intelectual e política. Ao final da leitura, mesmo a impressão podendo ser a de que os autores teriam muito mais a dizer sobre os temas que mobilizam, vislumbramos que o caminho pela história que se pretende transnacional, ou global, é possível quando os historiadores a realizam a partir de perspectivas comprometidas com a própria dinâmica complexa de seus objetos e dos espaços em que estão inseridos. A riqueza da investigação histórica sobre os protestos, os movimentos sociais na América 
Latina, surge nas similaridades entre as experiências, mas também e principalmente nas interconexões que suas diferenças e especificidades suscitam em cada lugar, aspectos muito bem delineados no livro.

Recebido em 17/08/2020

Aprovado em 07/09/2020 